\title{
FUNDO PÚBLICO E ORÇAMENTO DA POLÍTICA DE ASSISTÊNCIA SOCIAL DE 2010 A 2012 NO BRASIL
}

J. M. S. FELIPPE
Instituto Federal de Educação, Ciência e Tecnologia Fluminense - IFF
jonisfelippe@gmail.com

\section{RESUMO}

Este artigo realiza uma análise crítica do orçamento da Política de Assistência Social no triênio 2010-2012, evidenciando o direcionamento adotado pelo governo federal na aplicação dos recursos nesta área. Para tanto, partindo de um debate teórico acerca do fundo público, compreendido como uma apropriação pelo Estado, principalmente na forma de tributos, de parcela dos valores produzidos socialmente pelo trabalho, busca-se demonstrar a participação crescente e basilar do financiamento estatal na reprodução das relações capitalistas contemporâneas. Em seguida, são tecidas breves considerações sobre as receitas e os gastos desse fundo no orçamento brasileiro, destacando alguns dos embates políticos que envolvem a sua distribuição entre as classes sociais. Por último, são apresentados e problematizados os dados colhidos no portal SIGA BRASIL e "Panorama Social da América Latina" da CEPAL, os quais comprovam o crescimento dos programas de transferência de renda focalizados no combate à pobreza como a principal estratégia adotada pelas políticas sociais no Brasil e nos demais países latino-americanos.

PALAVRAS-CHAVE: Fundo público, Política Social, Assistência Social.

\section{PUBLIC FUND AND BUDGET OF SOCIAL ASSISTANCE POLICY 2010-2012 IN BRAZIL}

\section{ABSTRACT}

This article presents a critical analysis of the budget of the Social Assistance Policy in the triennium 2010-2012, reflecting the attitudes adopted by the federal government in the application of resources in this area. Thus, from a theoretical debate about the public fund, understood as an appropriation by the state, mostly in the form of taxes, of part the value produced by social work, the objective is to demonstrate the growing participation and funding of the state in reproduction of contemporary capitalist relations. Are then woven brief considerations on revenues and expenditures of the fund in the Brazilian budget, highlighting some of the political struggles involving its distribution among social classes. Finally, are presented and discussed the data collected in the portal SIGA BRASIL and in the "Panorama Social da América Latina" of CEPAL, which show growth of targeted cash transfer programs to combat poverty as the main strategy adopted by social policies in Brazil and other Latin American countries.

KEYWORDS: Public fund, Social Policy, Social Assistance. 


\section{INTRODUÇÃO}

Há algumas décadas, o debate acerca dos papéis desempenhados pelo Estado no movimento de acumulação capitalista vem ganhando destaque no âmbito dos estudos marxistas. Entretanto, como salienta Mandel (1982), das três funções exercidas por esta instituição (criação de condições gerais de produção; repressão às ameaças das classes dominadas; integração pela propagação ideológica), a primeira não havia sido tão investigada como as demais.

Com o passar dos anos, contudo, o próprio Mandel (1982) e, posteriormente, pensadores como Harvey (2009 e 2011) e lanni (2004) dedicaram-se à reflexão sobre o tema, desvelando as conexões cada vez maiores e mais essenciais entre a ação da máquina pública e o processo de valorização.

Nesse contexto, um assunto que merece especial atenção é o debate acerca do fundo público, já que é por meio dele, principalmente com a sua ampliação após o fim da Segunda Guerra Mundial, que o Estado operacionaliza suas intervenções, entre as quais têm se destacado: a realização de obras públicas para incentivar o emprego e criar infraestrutura para as empresas privadas; a intermediação das negociações entre as classes sociais; a criação de um sistema de seguridade social e salários indiretos, incentivando o consumo e garantindo a reprodução dos trabalhadores; os subsídios diretos e indiretos ao capital; a produção de matérias-primas e a estatização de setores estratégicos, mas pouco lucrativos para o setor privado; o incentivo à indústria bélica e ao desenvolvimento de novas tecnologias passíveis de incorporação à produção etc.

No que tange à reprodução da força de trabalho, uma das políticas com maior destaque atualmente no Brasil e na América Latina é a Assistência Social. Integrante da Seguridade Social, no caso nacional, ela possui um caráter não contributivo e está regulamentada como direito do cidadão e dever do Estado, conforme a LOAS ${ }^{1}$. Sua execução, porém, careceu de um sistema de gestão e de um conjunto continuado de serviços e ações até 2004, estando seu orçamento limitado aos recursos destinados aos benefícios constitucionais.

Nos últimos anos, todavia, o orçamento do Ministério do Desenvolvimento Social e Combate à Fome (MDS) experimentou um considerável crescimento, principalmente por conta da criação e expansão do Programa Bolsa Família (PBF). Nessa direção, este artigo, resgatando o debate teórico-crítico sobre a categoria fundo público, buscará problematizar os dados orçamentários da política em voga, comparando-os com o gato social dos demais países latinoamericanos, com orçamento geral brasileiro e com os valores destinados ao pagamento da dívida pública no triênio 2010-2012.

\section{ESTADO, FUNDO PÚBLICO E VALOR}

Um dos primeiros escritores a abordar a questão do fundo público foi Oliveira (1998). Segundo ele, durante o Welfare State nos países centrais, um novo padrão de financiamento público foi construído com o advento das propostas keynesianas, fazendo com que o investimento estatal passasse a participar de forma regular da reprodução tanto do capital quanto das condições

\footnotetext{
${ }^{1}$ Lei Orgânica da Assistência Social.
} 
de vida da classe trabalhadora. Com o tempo, a contribuição deste fundo para a manutenção da dinâmica social tornou-se insubstituível, passando a ser objeto de disputas entre os mais diversos grupos políticos e econômicos. Tais embates, por sua vez, subsidiaram a construção efetiva de uma esfera pública, de uma economia de mercado regulada pela luta entre as classes sociais.

No entanto, sem desconsiderar as contribuições oferecidas por Oliveira (1998), devem-se registrar algumas fragilidades de suas argumentações seguintes. O professor acredita que a importância adquirida pelo financiamento público teria levado à desmercantilização da força de trabalho e à anulação do fetichismo da mercadoria ${ }^{2}$, na medida em que há uma redução da extração de mais-valor com a suposta centralidade adquirida pelo fundo público (entendido como antivalor). Nas suas colocações, as relações entre o capital e o trabalho parecem ter sido reconfiguradas, fazendo com que um não dependa mais diretamente do outro para manter-se.

As inovações tecnológicas, dessa maneira, passariam a surgir independentemente do preço da força trabalho, e a reprodução do proletariado estaria mais vinculada aos salários indiretos (bens e serviços sociais - antimercadorias, pois não geram lucro) do que aos diretos. Como se percebe, tanto o fundo quanto os benefícios e serviços públicos seriam desprovidos de valor; o que representa um importante equivoco teórico.

Recorrendo aos escritos de Marx (2013), é possível identificar os elementos necessários para superar criticamente as propostas de Oliveira (1998). O filósofo alemão compreende o trabalho como a categoria ontológica mediadora entre o homem e natureza para a satisfação de necessidades fisiológicas e/ou sociais, as quais, uma vez sanadas, geram novas demandas e exigem novas mediações. Em que pese a tal pressuposto, essa atividade produtiva pode ser considerada sobre um duplo aspecto: como trabalho abstrato ou simples e como trabalho concreto. Sob o primeiro ponto de vista, constitui-se no dispêndio de energia física e intelectual empregada por qualquer indivíduo na produção de um bem, possuindo, por conseguinte, um caráter quantitativo, possível de ser mensurado a partir do tempo utilizado para a realização do feito; sob o segundo, deve ser considerado no seu caráter qualitativo, enquanto uma atividade material que gera um produto capaz de satisfazer determinadas necessidades.

Nesse sentido, a partir da ótica do trabalho abstrato, tem-se a produção de valores, ou seja, de tempo de trabalho condensado no corpo de produtos ou serviços, enquanto que, pela segunda ótica, tem-se a geração de valores de uso (tendo a natureza um papel fundamental ao proporcionar as matérias-primas). Desse modo, por se tratar do dispêndio simples de energia medido temporalmente, o trabalho abstrato é o elemento comum agregado a qualquer matéria, independentemente da sua utilidade. Sua quantificação possibilita a comparação de objetos qualitativamente distintos numa possível troca, além da acumulação de mercadorias, mais comumente expressas na forma de equivalente geral (dinheiro).

Embora não possa prescindir da construção de valores de uso, pois não se produzem, muito menos se adquirem bens que não atendam a alguma demanda - seja ela do corpo ou do espírito, como afirma Marx (2013) - o capitalismo, diferentemente de experiências sociais anteriores, generaliza e dá centralidade à produção e constante movimentação do valor. Essas diretrizes ainda

\footnotetext{
${ }^{2}$ Fenômeno próprio da sociedade capitalista identificado por Marx (2013), no qual as relações entre as pessoas, bem como o trabalho empregado na produção dos bens, ficam escamoteados, aparentando ter sido substituídos por relações entre coisas. Esse processo, juntamente com a centralidade adquirida pela troca, produz a ilusão de que as mercadorias possuem vida própria.
} 
permanecem na direção da sociedade atual, demonstrando que a extração de tempo de trabalho continua sendo o objetivo primordial da economia, inclusive pela permanente mercantilização de atividades e setores até então "desvinculados" da produção em moldes capitalistas (SINGER, 1977).

Além disso, ao contrário do que sugere a interpretação do texto de Oliveira (1998), a diminuição dos vínculos de trabalho formal conquistados na "Era de ouro" e a ressurreição de tipos arcaicos informais e paternalistas não representam uma autonomia da força de trabalho, como bem desenvolveu Harvey (2009). Na realidade, esses fatos históricos evidenciam as novas configurações e facetas impostas pelo capital para burlar as conquistas da classe proletária e potencializar o volume de mais-valia apropriado.

Outro ponto a ser enfatizado diz respeito à mundialização e à internacionalização econômica, pois, com o crescimento do sistema financeiro, as constantes inovações do mercado, a diminuição do período de rotação do capital (tempo entre a produção, a circulação e metamorfose do capital-mercadoria em dinheiro) e os investimentos na geração de valor tornaram-se mais arriscados. Por isso, a necessidade de suporte da máquina pública para prever, evitar e/ou compensar prejuízos aumentou. Nessa visão, a dependência do Capital em relação ao crescimento das funções do Estado não aponta para o fortalecimento da esfera pública, mas sinaliza o fato de o sistema "sofrer de uma doença incurável" (MANDEL, 1982, p. 341) que já inviabiliza a sua autorreprodução.

Por outro lado, a formação do fundo público e a possibilidade de empregá-lo diretamente ou como subsídio na construção ou modificação de bens materiais e na reprodução das classes não pode resultar de outro lugar senão do trabalho. Como salienta Behring (2008, 2010, 2012), os recursos que compõem este fundo são oriundos da apropriação feita pela máquina pública dos valores construídos socialmente, ou seja, de parte do trabalho abstrato na forma de mais-valia, juros, salários e rendas, sobre os quais incidem os tributos, conforme fórmula trinitária revelada por Marx (1983). Também é possível acrescentar o resultado da atuação de empresas produtivas estatais.

Assim, os benefícios e serviços oferecidos pelo Estado não podem ser considerados como antimercadorias, do mesmo modo que o fundo público não pode ser tratado como antivalor. Nos dois casos, o valor é o elemento central, o qual é recolhido e redistribuído pela máquina pública de acordo com o resultado da dualidade insuperável do capitalismo: os conflitos entre e intraclasses.

Nesse ponto, cabe resgatar brevemente a maneira como se compõe e se dá a repartição do fundo público no Brasil, evidenciando sua apresentação por meio do orçamento.

\section{ORÇAMENTO E FUNDO PÚBLICO NO BRASIL}

Historicamente, o volume de recursos a compor o fundo público no Brasil foi se alterando na mesma proporção em que o capitalismo se consolidava como modo de organização da produção. Quanto mais se aprofundavam as relações fundadas no trabalho livre e assalariado, mais a economia tornava-se dependente da intervenção estatal nas diversas esferas da vida social.

Segundo os dados fornecidos por Fabrício Augusto de Oliveira (2009), num período de cerca de 60 anos (de 1930 até os anos da década de 1990), a carga tributária e os gastos públicos subiram 
de $15 \%$ do valor do Produto Interno Bruto (PIB) para algo em torno de $35 \%$. Nos dias atuais, segundo Behring (2008), os números chegam a $37 \%$.

Engana-se, porém, quem acredita no fato de que a ampliação da arrecadação e das despesas governamentais ocorreu durante governos populares ou esteve acompanhada de um grande investimento na área social. Contraditoriamente ou não, o crescimento mais significativo do fundo e da participação do Estado na reprodução da vida social se deu nos períodos de 19651975 e 1990-2002, governos militar e neoliberal respectivamente, completamente alinhados com as recomendações do capital internacional (embora com características distintas).

Entre 1965 e 1975, houve um aumento de cerca de 10\% na carga tributária, a qual passou a absorver $25 \%$ da soma das riquezas produzidas no país. Já no caso dos governos dos anos de 1990, Collor e Fernando Henrique Cardoso, a arrecadação saltou de $25 \%$ para $35 \%$ do PIB. No entanto, na fase mais recente, os ajustes implementados estavam comprometidos com o crescimento da receita estatal para o pagamento de juros e encargos da dívida pública (OLIVEIRA, 2009), embora esta tenha apresentado um crescimento significativo na mesma década.

No bojo dessas modificações, foram criados mecanismos e políticas econômicas como a Lei de Responsabilidade Fiscal (LRF) em 2000 e, principalmente, a Desvinculação de Receitas da União (DRU) em 1994, que permite a retirada de $20 \%$ dos impostos e contribuições sociais destinados ao Orçamento da Seguridade Social (OSS) para a composição dos recursos fiscais, os quais são utilizados muitas vezes para pagamento de dívida interna e externa. Salvador (2010) ainda aponta outros graves equívocos que comprometem os recursos da seguridade, dentre eles a inclusão de despesas do orçamento geral nos gastos do OSS, como o pagamento de aposentadorias e outros benefícios de servidores públicos vinculados ao regime próprio de previdência e o financiamento de órgãos não associados ao OSS - Fundo de Saúde Militar, Ministério da Justiça, Ministério da Educação etc.

Não obstante, outro assunto que merece destaque é considerado nos estudos de Oliveira (2009): trata-se do peso ocupado pelas despesas obrigatórias (protegidas legalmente) no orçamento federal, principalmente com a inclusão do superávit primário nas metas prioritárias do governo a partir de 1999. Esse processo busca promover o enxugamento dos gastos públicos para garantir uma receita positiva do quantitativo de arrecadações, excluindo e dando prioridade ao pagamento da dívida. Segundo o autor, a margem de liberdade para a realização de escolhas por parte da gestão federal passou a girar em torno de $8,5 \%$ do total de recursos absorvido pelo Estado em 2000, o que representa um enrijecimento das possibilidades e das opções do Poder Executivo.

Apesar de terem avançado na estruturação e na redistribuição dos valores para determinadas áreas (enfatizando, por exemplo, a Política de Assistência Social), os governos a partir de 2003 (Lula e Dilma) não promoveram alterações estruturais na composição das receitas federais e na prioridade conferida aos encargos com os pagamentos e amortizações da dívida. Contudo, algumas mudanças positivas podem ser identificadas desde então, tais como: a maior divulgação dos valores desvinculados da seguridade social pela DRU a partir de 2005; a clarificação e a facilitação do acesso aos dados do orçamento; o aumento (ainda insuficiente) dos recursos destinados à população mais empobrecida, com destaque para a organização e institucionalização de um sistema de gestão da Assistência Social (política sobre a qual este artigo irá se deter) etc.

Nesse ponto, destaca-se a formulação da Política Nacional de Assistência Social (PNAS) e a criação do MDS, ambos em 2004, além da construção do Sistema Único de Assistência Social 
(SUAS), por meio de equipamentos e programas padronizados, e da ampliação dos programas e benefícios de transferência de renda como o Benefício de Prestação Continuada (BPC) e o Bolsa Família. Mesmo com todas as críticas e ressalvas possíveis, investimentos como esses têm proporcionado uma diminuição dos índices de pobreza via crescimento progressivo da participação do fundo público na reprodução dos segmentos mais pauperizados da classe trabalhadora, conforme dados da Pesquisa Nacional por Amostra de Domicílios (PNAD) (IBGE, 2012).

Esse processo está articulado a um movimento mundial de transmutação das políticas sociais em políticas de combate à pobreza (FREIRE, 2013), o que muitas vezes se traduz em minimalização e focalização dos serviços sem o compromisso com a construção de direitos sociais mais efetivos. Como demostram os dados da CEPAL (2012), a partir dos anos 2000, diversos países da América Latina aumentaram significativamente o gasto com as ações de Assistência Social voltadas para o enfrentamento da pobreza. É o caso da Argentina, que aumentou 85\%, da Costa Rica, cerca de $75 \%$, e da Colômbia, que quase dobrou o montante destinado aos serviços.

Nesse sentido, se se levam em conta a importância adquirida pelo fundo público nos últimos cinquenta anos no Brasil e as modificações e embates que têm cercado a elaboração do orçamento e de suas prioridades (principalmente no que tange às parcelas que serão destinadas ao capital financeiro e à reprodução da força de trabalho), percebe-se a necessidade de compreendê-lo para além de uma simples disposição de receitas e despesas da máquina pública, configurando-se, na realidade, como uma

[...] importante arena de negociação, na qual se decide como se distribuirá o ônus da tributação entre os membros da sociedade e quem ou quais setores se beneficiarão com sua destinação/uso, em função das prioridades públicas estabelecidas como resultado dos embates que se travam entre as forças políticas representadas nos Poderes Executivo e Legislativo no processo de escolhas dos programas governamentais.

O orçamento pode ser visto, portanto, como o espelho da vida política de uma sociedade, uma vez que registra e revela, em sua estrutura de gastos e receitas, sobre que classe ou fração de classe recai o maior ou o menor ônus da tributação e as que mais se beneficiam com os seus gastos (OLIVEIRA, 2009, p. 87).

\section{FUNDO PÚBLICO E ORÇAMENTO DA POLÍTICA DA ASSISTÊNCIA SOCIAL DE 2010 A 2012}

Como já foi sinalizado, uma das políticas sociais que mais tem ganhado destaque nos últimos dez anos no Brasil e nos demais países latino-americanos é a Assistência Social. Os recursos destinados à sua operacionalização cresceram no decorrer do governo Lula (2003-2010), tendo esse movimento se mantido a partir de 2011 na gestão da presidente Dilma Rousseff, como buscarse-á demonstrar.

Segundo Salvador (2010), de 2004 a 2007, os investimentos na política em questão cresceram 48,38\% somente em relação ao Fundo Nacional de Assistência Social (FNAS), responsável pela execução de serviços e ações continuadas, programas e projetos e pelo pagamento do Benefício de Prestação Continuada (BPC) e da Renda Mensal Vitalícia (RMV). Fora do FNAS, ainda foram liquidados, em 2006, 10 bilhões de reais com o PBF, o que representava 
cerca de $30 \%$ de todo o orçamento do MDS na época (OLIVEIRA, 2009, p. 159). Os dados da CEPAL (2012) apontam para um crescimento ainda mais significativo entre 2000 e 2007, com a triplicação dos valores destinados à pasta.

Atualmente, o volume de gastos com a Assistência Social continua num movimento ascendente. De 2010 até 2012, ocorreu um aumento de 23,7\% nos investimentos nessa área, o que demonstra um acréscimo de 9 bilhões no caixa da pasta ministerial (saltando de 39,4 bilhões para 48,7 bilhões nesses três anos), conforme Figura 1. Cabe destacar que todos os dados apresentados por elaboração própria do autor foram retirados do Sistema Integrado de Informações do Governo Federal (SIAFI), estando disponíveis no portal SIGA BRASIL. Os valores foram categorizados e deflacionados pelo autor com base no IGP-DI (tendo 2010 como ano base).

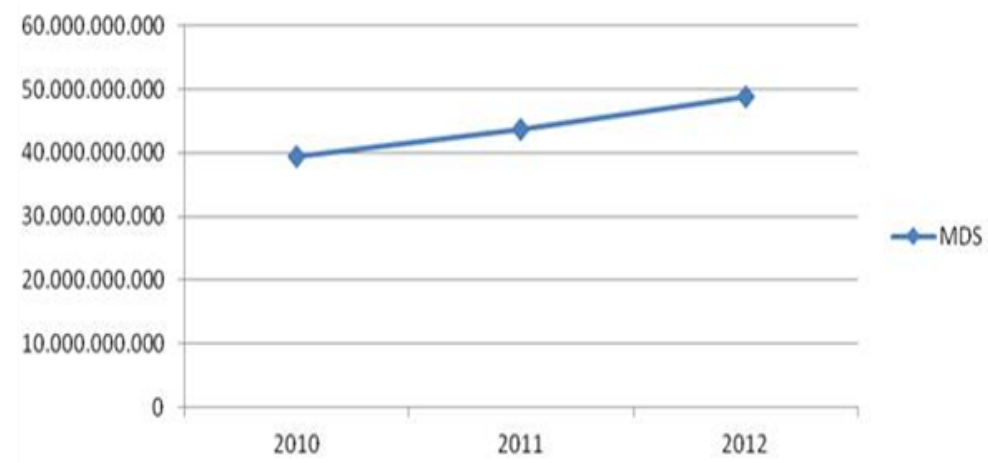

Figura 1: Evolução dos recursos do MDS no triênio 2010-2012 Fonte: SIAFI/SIGA (elaboração própria).

Os recursos da política mantiveram o mesmo direcionamento identificado por Oliveira (2009) e Salvador (2010). Os dois autores já haviam demonstrado em suas pesquisas a centralidade adquirida pelos programas e benefícios baseados na transferência monetária de renda desde 2004. Assim, se em 2006 o Bolsa Família era responsável por 30\% dos valores destinados ao MDS, em 2010 a proporção chegou a 36\% e, em 2012, a 38\%, representando um volume total de cerca de 18,5 bilhões de reais neste último ano.
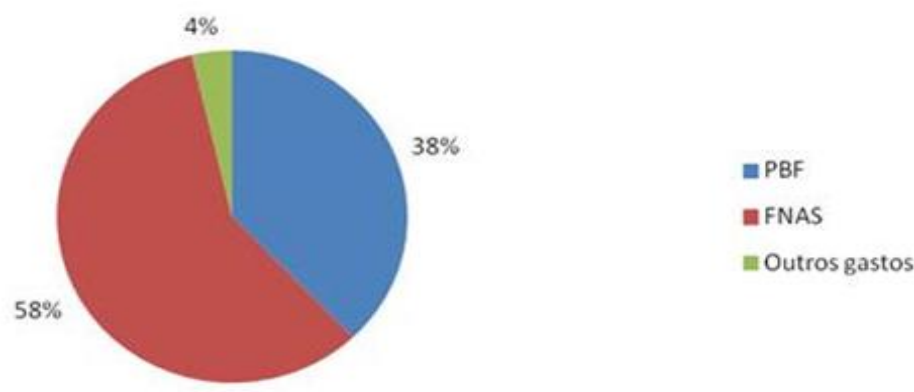

Figura 2: Divisão dos recursos do MDS em 2012. Fonte: SIAFI/SIGA (elaboração própria).

Somente de 2010 a 2012, foi registrado um acréscimo de $\mathrm{R} \$ 4,4$ bilhões (31,3\%) nos gastos com o PBF. Além disso, o BPC, juntamente com a RMV, representa em torno de $93 \%$ de todo o dinheiro movimentado pelo FNAS. Dessa forma, a soma dos recursos utilizados para o pagamento e a operacionalização das três ações de transferência de renda (PBF, BPC e RMV) comprometeu 93\% de todos os valores destinados ao MDS em 2012. 


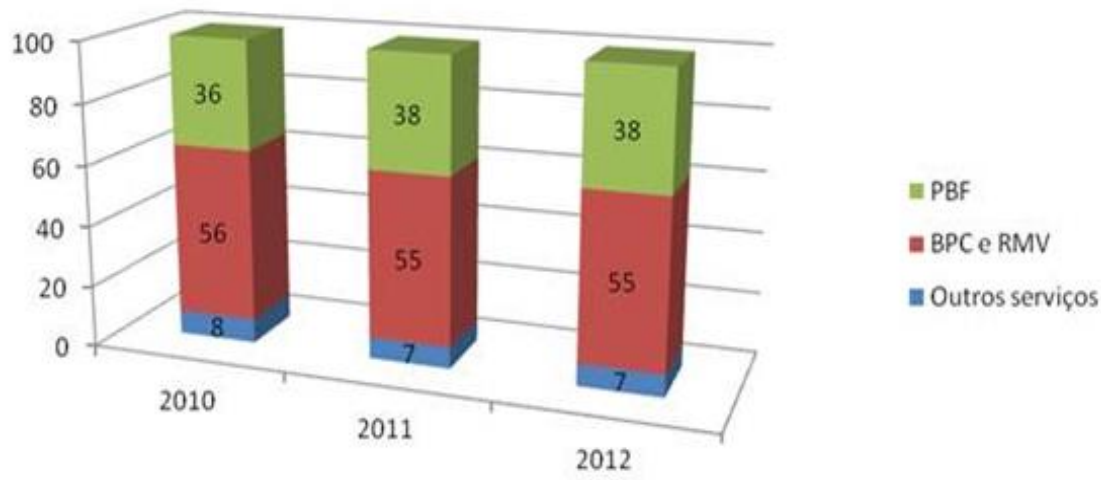

Figura 3: Comprometimento dos recursos do MDS com pagamento de benefícios. Fonte: SIAFI/SIGA (elaboração própria).

Conforme argumento já apresentado, trata-se de uma variação positiva na porcentagem do orçamento destinada a financiar os programas de transferência de renda com enfoque no combate à pobreza, conforme tendência presente nos demais países da América Latina e não apenas no Brasil. Dessa maneira, é possível visualizar na Figura abaixo que a média de aumento dos recursos destinados à Seguridade e à Assistência Social apresentou variação maior do que os destinados às demais políticas setoriais no conjunto das vinte e uma nações. Como detalha a CEPAL (2012), apesar dos índices aglutinarem também os gastos com seguridade (previdência), o crescimento está diretamente relacionado com o reforço dos programas de assistenciais (o que envolve essencialmente transferências de renda condicionadas ou não).

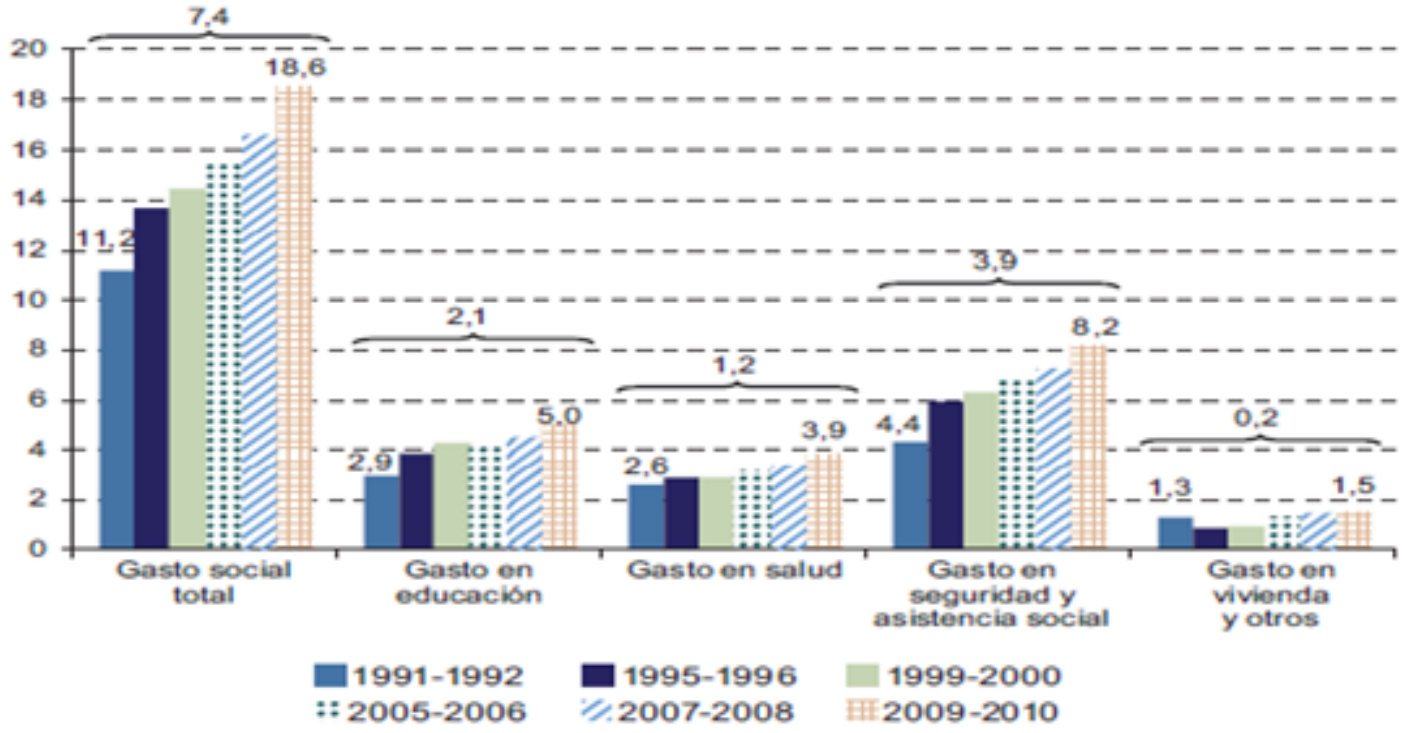

Figura 4: América Latina e Caribe (21 países) - evolução do gasto público social por setores de 2009 a 2010 (em porcentagem do PIB).

Fonte: CEPAL (2012).

Mesmo considerando a pertinência das críticas contra esse modelo de Assistência Social adotado nos últimos anos pelos países latino-americanos, não seria possível ignorar o poder redistributivo alcançado pelo conjunto dessas ações. No caso do Brasil, o aumento da capacidade de compra do salário mínimo, a diminuição da idade para acesso ao BPC (atualmente 65 anos) e a implementação do PBF foram certamente os principais responsáveis por "retirar um contingente nada desprezível da população da condição de pobreza" (OLIVEIRA, 2009, p. 159). As informações 
trazidas pela PNAD demonstram essa tendência de redução nos níveis de desigualdade de renda (apesar de esta ser uma característica ainda muito presente no país).

De 2001 a 2011, foi possível observar que os indivíduos que integram a parcela dos 20\% mais ricos do país tiveram uma diminuição de quase $10 \%$ na apropriação dos rendimentos nacionais (de $63,7 \%$ para $57,7 \%$ ), enquanto a participação dos $20 \%$ mais pobres saiu de $2,7 \%$ para $3,5 \%$. Nesse sentido, apesar do fosso entre os mais ricos e os mais pobres ainda ser extremamente grande, registrou-se uma diminuição importante no Coeficiente de $\mathrm{Gini}^{3}$ de todas as fontes de renda (índice utilizado para medir a desigualdade social no mundo) entre os anos de 2001 e 2011, saindo de 0,572 para 0,507 (IBGE, 2012). Em 2012, o índice tem se mantido estável.

Internacionalmente os resultados também são bastante expressivos. Segundo informações da CEPAL (2012), a taxa de pobreza teve queda significativa no decorrer dos anos 2000 no conjunto de países que apresentaram investimentos significativos na área social na América Latina. Somente entre os anos de 2010 e 2011, por exemplo, a taxa de pobreza teve queda de mais de 5\% no Paraguai, mais de 3\% no Perú e no Equador e entre 2\% e 3\% na Argentina, na Colômbia e no Brasil. Veja abaixo as alterações nos percentuais da população em faixas de pobreza e indigência em alguns dos países:

Tabela 1: Magnitude da pobreza e da indigência

\begin{tabular}{|c|c|c|c|c|c|c|c|}
\hline \multirow[b]{2}{*}{ Pais } & \multirow[b]{2}{*}{ Ano } & \multicolumn{3}{|c|}{$\begin{array}{l}\text { Populaçá abaío da linha da } \\
\text { pobreza }\end{array}$} & \multicolumn{3}{|c|}{$\begin{array}{l}\text { Populaçáo abaío da linha da } \\
\text { indigéncia }\end{array}$} \\
\hline & & $\begin{array}{c}\text { Toal do } \\
\text { pais }\end{array}$ & $\begin{array}{l}\text { Zonas } \\
\text { urbanas }\end{array}$ & $\begin{array}{l}\text { Zonas } \\
\text { rurais }\end{array}$ & $\begin{array}{c}\text { Total do } \\
\text { pais }\end{array}$ & $\begin{array}{l}\text { Zonas } \\
\text { urbanas }\end{array}$ & $\begin{array}{l}\text { Zonas } \\
\text { rurais }\end{array}$ \\
\hline Argentina & $\begin{array}{l}2002 \\
2006 \\
2011\end{array}$ & $\ldots$. & $\begin{array}{c}45,4 \\
24,8 \\
5,7\end{array}$ & $\ldots$ & $\ldots$ & $\begin{array}{c}20,9 \\
9,6 \\
1,9 \\
\end{array}$ & $\ldots$ \\
\hline Bolivia & $\begin{array}{l}2002 \\
2007 \\
2009 \\
\end{array}$ & $\begin{array}{l}62,4 \\
54,0 \\
42,4\end{array}$ & $\begin{array}{l}52,0 \\
42,4 \\
32,6\end{array}$ & $\begin{array}{l}79,2 \\
75,8 \\
61,5\end{array}$ & $\begin{array}{l}37,1 \\
31,2 \\
22,4\end{array}$ & $\begin{array}{l}21,3 \\
16,2 \\
11,9\end{array}$ & $\begin{array}{l}62,9 \\
59,0 \\
43,0\end{array}$ \\
\hline Brasil & $\begin{array}{l}2002 \\
2006 \\
2011\end{array}$ & $\begin{array}{l}37,8 \\
33,4 \\
20,9\end{array}$ & $\begin{array}{l}34,4 \\
30,0 \\
18,2\end{array}$ & $\begin{array}{l}55,7 \\
50,1 \\
36,1\end{array}$ & $\begin{array}{c}12,6 \\
9,0 \\
6,1\end{array}$ & $\begin{array}{l}10,0 \\
6,7 \\
4,5\end{array}$ & $\begin{array}{l}26,4 \\
20,5 \\
14,9\end{array}$ \\
\hline Chile & $\begin{array}{l}2000 \\
2006 \\
2011\end{array}$ & $\begin{array}{l}20,2 \\
13,7 \\
11,0\end{array}$ & $\begin{array}{l}19,7 \\
13,9 \\
11,3\end{array}$ & $\begin{array}{c}23,7 \\
12,3 \\
8,7\end{array}$ & $\begin{array}{l}5,6 \\
3,2 \\
3,1\end{array}$ & $\begin{array}{l}5,1 \\
3,2 \\
3,0\end{array}$ & $\begin{array}{l}8,4 \\
3,5 \\
3,8\end{array}$ \\
\hline Equador & $\begin{array}{l}2004 \\
2009 \\
2011\end{array}$ & $\begin{array}{l}51,2 \\
42,2 \\
35,4\end{array}$ & $\begin{array}{l}47,5 \\
40,2 \\
32,4\end{array}$ & $\begin{array}{l}58,5 \\
46,3 \\
41,4\end{array}$ & $\begin{array}{l}22,3 \\
18,1 \\
13,9\end{array}$ & $\begin{array}{l}18,2 \\
15,5 \\
10,1\end{array}$ & $\begin{array}{l}30,5 \\
23,3 \\
21,3\end{array}$ \\
\hline Uruguai & $\begin{array}{l}2007 \\
2009 \\
2011\end{array}$ & $\begin{array}{c}17,7 \\
10,4 \\
6,5\end{array}$ & $\begin{array}{c}18,1 \\
10,7 \\
6,7\end{array}$ & $\begin{array}{c}12,6 \\
5,9 \\
4,1\end{array}$ & $\begin{array}{l}3,0 \\
1,9 \\
1,1\end{array}$ & $\begin{array}{l}3,1 \\
2,0 \\
1,1\end{array}$ & $\begin{array}{l}2,4 \\
1,3 \\
0,6\end{array}$ \\
\hline
\end{tabular}

Fonte: CEPAL (2012).

Os pontos positivos, todavia, não podem impedir a averiguação das verdadeiras prioridades do fundo público, especialmente no caso do brasileiro (foco desse trabalho). Na forma como foi problematizado, sendo o orçamento um campo de lutas e embates políticos entre os grupos e as classes sociais, quem realmente tem "ficado com a vantagem" é o capital financeiro e portador de juros, tanto nacional quanto internacional, apesar das variações registradas. Da receita total arrecadada em 2012 (cerca de 1,7 trilhão de reais), 33,4\% (R\$573,5 bilhões) foram utilizados para

\footnotetext{
${ }^{3}$ Coeficiente utilizado para aferir níveis de igualdade e de desigualdade da seguinte forma: quanto mais próximo de um, maior a desigualdade; quanto mais próximo de zero, maior a igualdade.
} 
amortizações e pagamento de juros da dívida pública; a proporção chegou a 41,5\% em 2011. Já a Política Assistência Social representou apenas 2,8\% de toda a arrecadação em 2012.

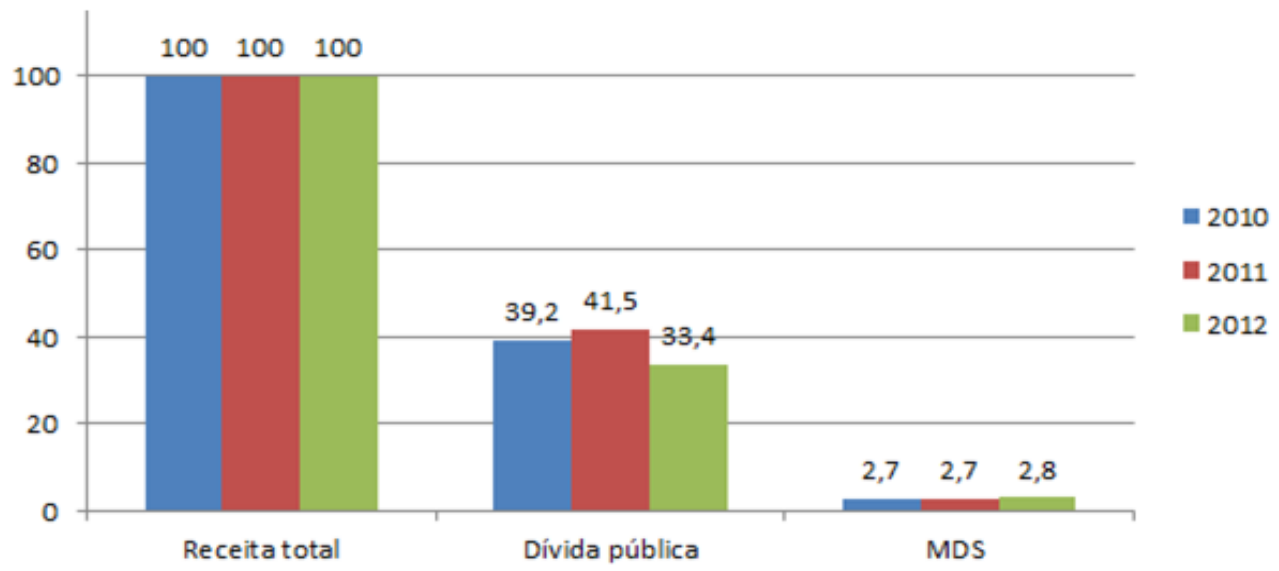

Figura 5: Comprometimento da receita total arrecada pelo Estado com o pagamento e amortização de dívida pública e com o financiamento da Assistência Social.

Fonte: CEPAL (2012).

De modo geral, os dados apontam que não existe uma ruptura entre a política econômica da década de 1990 e a adotada pelo Brasil nos últimos anos. Ao contrário, apesar do destaque adquirido pela Assistência Social a partir do ano de 2003, dos avanços significativos nos seus modelos de gestão e regulação, bem como da diminuição dos níveis de desigualdade social na última década, o capital portador de juros continua sendo o principal destino do fundo público no país.

Considerando a hipótese apresentada por Freire (2013) e a tendência similar verificada no Brasil e nos demais países latino-americanos (Argentina, Chile, Uruguai, Colômbia, entre outros) no que se refere à gestão do gasto social, pode-se inferir que o crescimento das Políticas de Assistência Social não alcançou e nem pretende qualquer alteração estrutural na base econômica (estrutura de classes). Embora traga resultados importantes na redução da pobreza e participe diretamente do processo de reprodução social de parte da população, as ações focalizadas nos grupos mais pauperizados não invalidam a centralidade da participação do fundo público no processo de acumulação capitalista. Ao contrário disso, fortalece tal processo pela inclusão de um contingente de pessoas, até então excluídas ou com pouca participação, nos circuitos de consumo.

\section{CONSIDERAÇÕES FINAIS}

O conjunto das informações e das discussões apresentado demonstra a relevância de se aprofundarem as reflexões críticas sobre o fundo público na contemporaneidade, objetivando a construção de estratégias que viabilizem o redirecionamento dos gastos governamentais, atualmente centrados na manutenção e na ampliação do processo de acumulação.

Partindo de uma abordagem marxista sobre a composição do fundo público, compreendido como uma parcela do valor construído coletivamente pelo trabalho e apropriado pelo Estado por meio de tributos ou atividades produtivas de empresas estatais, buscou-se destacar a sua fundamentalidade para a ampliação do capital e a reprodução da classe trabalhadora. Entretanto, essa averiguação não corrobora com as propostas que apontam para o surgimento de um novo modo de produção ou para a desintegração das relações capitalistas. De encontro com essa visão, 
destacou-se a agudização das contradições dessa dinâmica societária e a sua dependência cada vez maior às intervenções da máquina pública.

Dessa maneira, também foram enfatizados alguns aspectos sobre a questão do fundo no Brasil. Os apontamentos destacaram as estratégias implementadas pelos governos da década de 1990, alinhados com as recomendações do receituário neoliberal, como a LRF e a DRU, ambas com a meta de ampliar e garantir vultosas quantias do orçamento federal para alimentar o capital portador de juros nacional e internacional.

Como foi visto, de $30 \%$ a $40 \%$ de toda a arrecadação governamental vem sendo utilizada com os encargos e amortizações da dívida pública. Nesse panorama, o OSS e, consequentemente, a reprodução da força de trabalho acumulam prejuízos diversos com as desvinculações e as inclusões de gastos próprios do orçamento geral no seu planejamento.

Apesar das constantes perdas, desde 2003 alguns avanços vêm sendo registrados no caso da Assistência Social, inclusive no que tange à regulamentação, à institucionalização e à padronização das ações. Mesmo com ênfase nos benefícios e programas de transferência monetária de renda, os dados da PNAD e da CEPAL (2012) confirmaram as alterações promovidas durante os últimos anos no Brasil e nos demais países da América Latina. Houve um crescimento constante no volume de recursos destinados à política, o que tem permitido uma participação maior dos segmentos mais pauperizados na distribuição da riqueza produzida socialmente (embora as desigualdades ainda sejam extremamente elevadas).

Desse modo, apesar das contradições e discrepâncias entre os gastos com o capital financeiro e a Assistência Social, as informações reafirmam o orçamento como um campo de lutas e embates entre as classes, assim como a possibilidade de conquistas consideráveis por parte dos trabalhadores, mesmo numa sociedade capitalista madura.

\section{REFERÊNCIAS BIBLIOGRÁFICAS}

1. BEHRING, E. Acumulação capitalista, fundo público e valor. IN: Política Social no Capitalismo: tendências contemporâneas. São Paulo: Cortez, 2008.

2. Crise do Capital, fundo público e valor. In: Capitalismo em crise, Política Social e Direitos. São Paulo: Cortez, 2010.

3. Rotação do Capital e Crise: fundamentos para compreender o fundo público e a política social. In: SALVADOR, E.; et al (Orgs.). Financeirização, Fundo público e Política Social. São Paulo: Cortez, 2012.

4. CEPAL. Panorama social de América Latina. Santiago: Naciones Unidas, 2012.

5. FREIRE, S. Políticas sociais para a pobreza: a pobreza das políticas. In: SOUZA, G. (Org.) O Social em perspectiva: Políticas, trabalho, Serviço Social. Maceió, EDUFAL, p. 47-61, 2013.

6. HARVEY, D. Condição pós-moderna. São Paulo: Loyola, 2009.

7. IANNI, O. Estado e Capitalismo. São Paulo: Brasiliense, 2004.

8. IBGE. Síntese de Indicadores Sociais: uma análise das condições de vida da população brasileira. Rio de Janeiro: IBGE: 2012.

9. MANDEL, E. Capitalismo tardio. São Paulo: Abril cultural, 1982. 
10. MARX, K. O capital. Livro I, volume I. Rio de Janeiro: Civilização Brasileira, 2013.

11. O capital. Volume III, tomo 2. São Paulo: Abril Cultural, 1983.

12. OLIVEIRA, F. Os direitos do antivalor: a economia política da hegemonia imperfeita. Petrópolis: Vozes, 1998.

13. OLIVEIRA, F. A. Economia e Política das Finanças Públicas no Brasil. São Paulo: Hucitec, 2009.

14. SALVADOR, E. Fundo público e Seguridade Social no Brasil. São Paulo: Cortez, 2010.

15. SIGA BRASIL. Execução Orçamentária. Disponível em: http://www12.senado.gov.br/orcamen to/sigabrasil. Acesso no dia 10 de setembro de 2013.

16. SINGER, P. Economia política do trabalho: elementos para uma análise histórico-estrutural do emprego e da força de trabalho no desenvolvimento capitalista. São Paulo: Hucitec, 1977. 